\title{
Correction to: RarERN Path: a methodology towards the optimisation of patients' care pathways in rare and complex diseases developed within the European Reference Networks
}

Rosaria Talarico', Sara Cannizzo², Valentina Lorenzoni², Diana Marinello ${ }^{1}$,laria Palla², Salvatore Pirri², Simone Ticciati ${ }^{1}$, Leopoldo Trieste ${ }^{2}$, Isotta Triulzi ${ }^{2}$, Enrique Terol ${ }^{3}$, Anna Bucher ${ }^{3}$ and Giuseppe Turchetti ${ }^{*}$

\section{Correction to: Orphanet J Rare Dis (2020) 15:347 https://doi.org/10.1186/s13023-020-01631 $-1$}

Following the publication of the original article [1] we were informed that the authors' given and family names had unfortunately been interchanged.

The correct author names are shown here below:

Rosaria Talarico, Sara Cannizzo, Valentina Lorenzoni, Diana Marinello, Ilaria Palla, Salvatore Pirri, Simone Ticciati, Leopoldo Trieste, Isotta Triulzi, Enrique Terol, Anna Bucher and Giuseppe Turchetti.

The author names have been corrected in the author list of this Correction and updated in the original article.
Della Libertà, 33, 56127 Pisa, Italy. ${ }^{3}$ DG Health and Food Safety, 1000 Brussels, Belgium.

Published online: 22 March 2021

Reference

1. Talarico, et al. RarERN Path: a methodology towards the optimisation of patients' care pathways in rare and complex diseases developed within the European Reference Networks. Orphanet J Rare Dis. 2020;15:347. https://doi.org/10.1186/s13023-020-01631-1.

\section{Publisher's Note}

Springer Nature remains neutral with regard to jurisdictional claims in published maps and institutional affiliations.

\section{Author details}

${ }^{1}$ Rheumatology Unit, Azienda Ospedaliero Universitaria Pisana, 56126 Pisa, Italy. ${ }^{2}$ Institute of Management, Scuola Superiore Sant'Anna, Piazza Martiri

(c) The Author(s) 2021. This article is licensed under a Creative Commons Attribution 4.0 International License, which permits use, sharing, adaptation, distribution and reproduction in any medium or format, as long as you give appropriate credit to the original author(s) and the source, provide a link to the Creative Commons licence, and indicate if changes were made. The images or other third party material in this article are included in the article's Creative Commons licence, unless indicated otherwise in a credit line to the material. If material is not included in the article's Creative Commons licence and your intended use is not permitted by statutory regulation or exceeds the permitted use, you will need to obtain permission directly from the copyright holder. To view a copy of this licence, visit http://creativecommons.org/licenses/by/4.0/. The Creative Commons Public Domain Dedication waiver (http://creativecommons.org/publicdomain/zero/1.0/) applies to the data made available in this article, unless otherwise stated in a credit line to the data. 